\title{
The lotus flower: biomimicry solutions in the built environment
}

\author{
Y. Nanaa \& H. Taleb \\ Sustainable Design of the Built Environment, \\ British University in Dubai, UAE
}

\begin{abstract}
In architecture, biomimicry gives us the chance to go beyond standard approaches to sustainable design and develop restorative solutions. We are looking to find solutions and natural approaches that might help move from the industrial age to an ecological age. When we talk of sustainable design, the final product is much more than a sustainable building that will merely live longer and consume less energy than its counterparts. A sustainable/environmental building must be one that provides high standards of comfort and well-being to dwellers. This paper focuses on inspiration by nature as a concept and the biomimicry case here is the lotus flower, with close analysis of its strategies for survival and coping with the surrounding environment in the most subtle of ways. This study sets out to analyse and mimic the strategies of the lotus flower into an existing building as a case study. The aim is to achieve the maximum use of natural sustainable energy available in the surrounding environment and natural concepts from biology to inspire a solution that will make the building more energy efficient. To evaluate the application of these strategies, Ecotect software was used and comparisons between the results of the building before and after applying those strategies will give a clear comprehension of the effectiveness of those strategies on the building's performance.

Keywords: biomimicry, eco-buildings, energy performance, sustainable built environment, Dubai, Ecotect, architecture, design.
\end{abstract}

\section{Introduction}

For the past 3.6 billion years, nature has been solving many of the problems that designers face today. Designing biologically inspired components into man-made 
products is called biomimicry. Some of the world's most famous inventors have used it from as early as the 15th century when Da Vinci, a superb engineer and keen observer of birds and their flights, put them into his sketches for a flying machine. Although he never made it, the first plane that did make it into the sky, made by the Wright brothers, was inspired by their observations of pigeons (Penman [1]).

In architecture, biomimicry gives us the chance to go beyond standard approaches to sustainable design and retrieve restorative solutions.

We are looking to find solutions and natural approaches that might 'help us to move from the industrial age to an ecological age' (Pawlyn [2]).

When we mention sustainable design, the final product is much more than a sustainable building that will merely live longer and consume less energy than its counterparts. A sustainable/environmental building must be one that provides high standards of comfort and well-being to dwellers.

\section{The natural concept}

Inspired by this concept, in this paper, the objectives for study of the existing building are to maximise the use of natural sustainable energy available in the surrounding environment and the natural concepts from biology, to discover potential modifications that will make the building more energy efficient, to less consume less and be less damaging to surrounding nature.

\subsection{The lotus flower}

The lotus flower is the natural concept chosen for biomimicry, the intention is to mimic the flower, not in terms of form, but rather the mechanisms and behaviour including reactions to light, thermal insulation, response to different atmospheres around it and the way it provides itself with energy to survive.

\subsubsection{Lesson one - light control}

The first and most significant behaviour of the lotus that can be an inspiration is the mechanism for opening and closing depending on the amount of daylight supplied around the plant.

\subsubsection{Lesson two - nourishing}

Another interesting and minimal approach we can learn from this flower is the way it nourishes itself by turning the water it absorbs into the glucose necessary for it to live. This is through photosynthesis, which is inspiration enough for selfsufficiency in natural beings and the way they depend on their own capabilities to produce their own power and consume it in silent grace.

\subsubsection{Lesson three - self shading}

Another lesson learnt from the structure of this plant is the self-shading technique that the higher leaves provide for the flower. That is to ensure that it is kept safe and protected from harsh solar lighting and that the seed pod stays secure until it ripens. 
These techniques from the flower will be applied to the building in different forms. The fact that the flower only absorbs as much light as needed each day teaches us to make the windows adjustable and fit to the need of tenants/residents. To open and close the second layer of windows there will be wooden shutters/louvres to adjust how much light is transmitted into the house each day.

The shading technique of the lotus leaves will be simulated by a great wooden shading panel covering the whole building, providing a better level of shelter for people to enjoy the roof in good weather and a much higher level insulation of heat through the roof to all residential units.

\section{The case study}

The building on which we conducted the thermal analysis is a regular residential building with a total of 3,000 square meters of area in the plot of which approximately half has been built.

This building is a regular building constructed according to the common concepts of architecture. It does provide relative comfort to the users and it is aesthetically appealing. However, the conventional use of electricity and the heavy use in the summer months of artificial air conditioning, added to the huge amount of glare on the southern elevation together raises sustainability questions. This is a challenge to us as architects to find better alternatives that could give results that are of the same quality, while at the same time making much less of an effect on the environment.

We can simplify weather data for Dubai as being extremely hot in the summer and far from comfort levels, while more moderate in the winter months with high glare, illumination, diffused radiation and relative humidity all year long.

\section{Simulation of current situation}

\subsection{Daylight analysis}

Maintaining a level of daylight that allows the least amount of artificial lighting possible is essential to ensure sustainable design and most importantly visual comfort for residents. Sunlight adds to life in any house, is consistent and sufficient and brightens up homes.

A closer look at the daylight analysis for both sides of the building shows more diffused and scattered lighting on the northern side, as opposed to more acute and direct lighting on the southern side. Both of these are acceptable with no glare or lack of lighting on either side.

\subsection{Heat gain}

Figure 1 shows the amount of sun a regular apartment from the south is exposed to in summer and winter. It is noticeable that the main heat gain is from the roof as well as the walls. With the amount of radiated heat from the sun in the Gulf region, a proposed strategy would be quite helpful to reduce heat gain. 


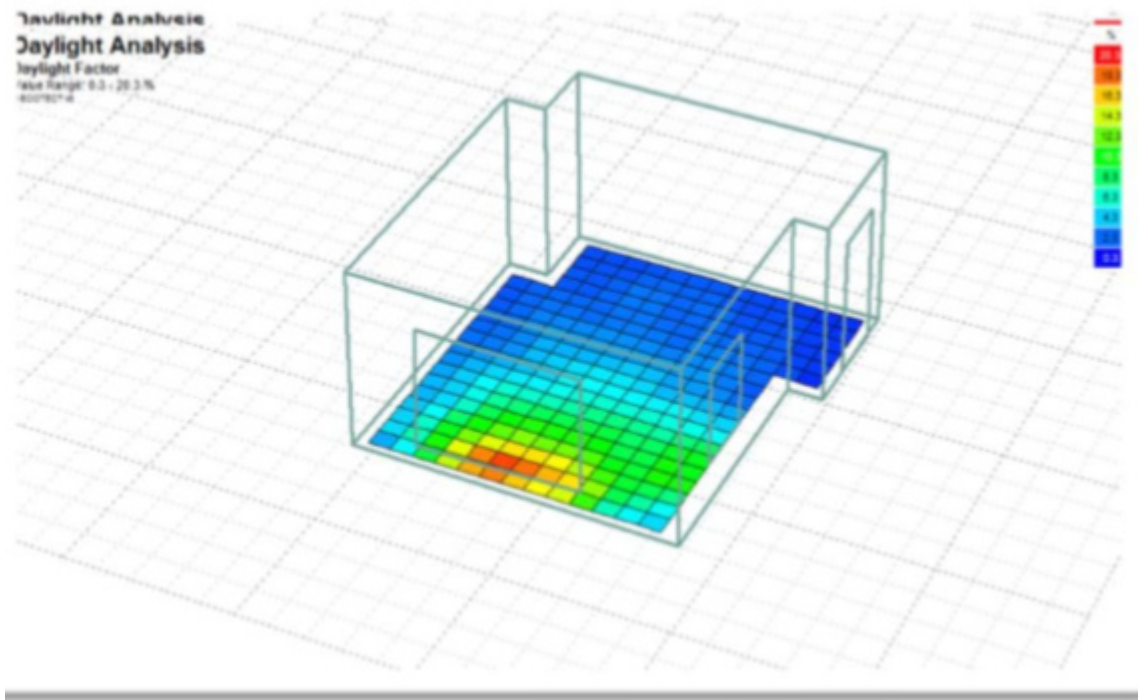

Figure 1: Daylight analysis of an apartment to the south.

\subsection{Hourly temperature profile}

Figure 2 below introduces us to hourly temperatures on a random day in each of: January, April and August.

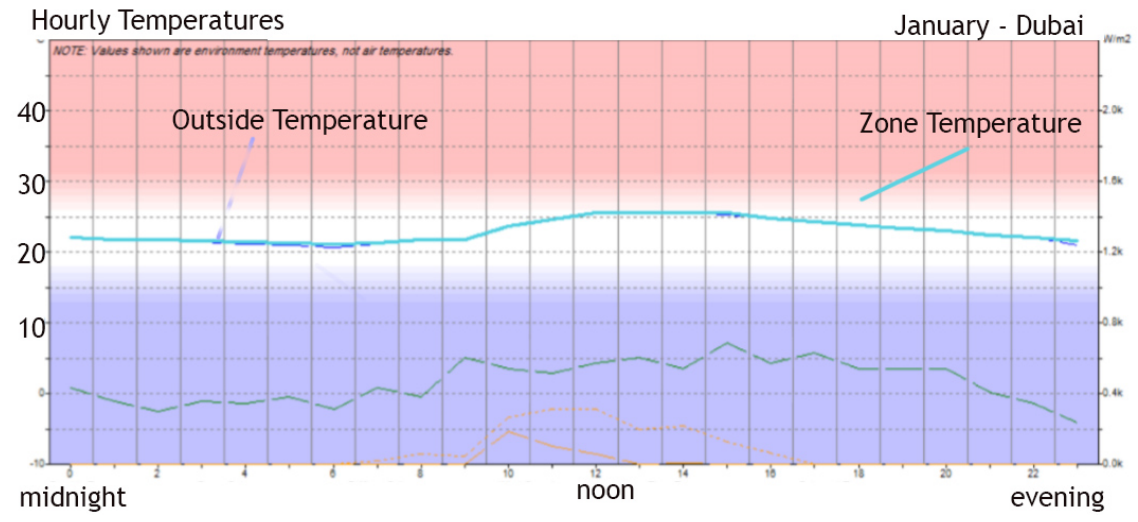

Figure 2: Hourly temperature profile January (Ecotect, 2014).

The darkest line is the zone temperature - the apartment - which is clearly falling into the comfort zone over all hours in January. This is a clear indication that, with sufficient ventilation and the correct orientation of the building we can minimise the HVAC load, then make best use of the surrounding environment and air currents by using the correct ventilation. The inside temperature of the room will be within the comfort zone with no artificial means. 
However, the hourly temperature profile showed a slight increase in the temperature in April (Figure 3), making it more difficult than January to maintain the comfort zone. Temperatures went up to almost $30^{\circ} \mathrm{C}$ at noon and stayed in the comfort zone the rest of the day. This suggests that we need a mixed mode system for such a month, with artificial air conditioning for a few hours during the day.

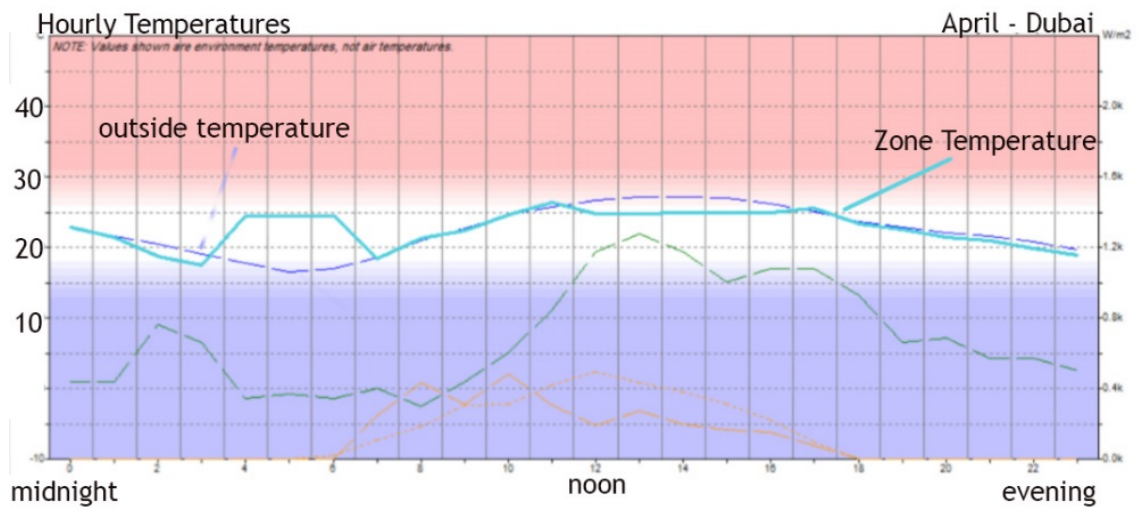

Figure 3: Hourly temperature profile April. (Ecotect 2014).

Figure 4 represents August and we can clearly see that the outside temperature peaks at a high of 40 and the reading inside the zone is little better, falling way over the comfort zone to as high as 35 degrees and artificial air conditioning is a must all day long. In the figures below we will start to assess how what the consumption of this zone is in terms of KWs across the year.

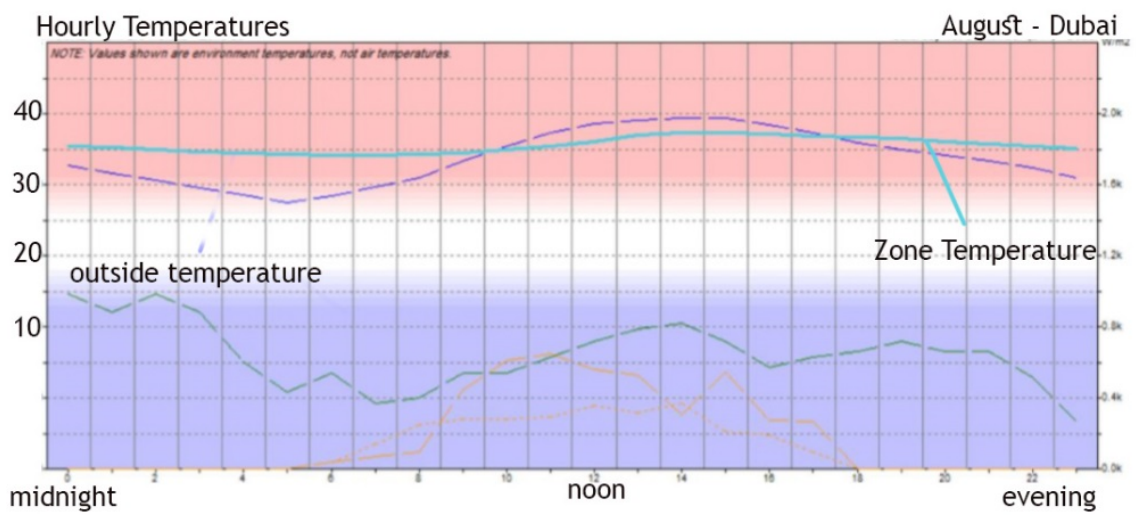

Figure 4: Hourly temperature profile August. 


\section{Proposed strategies}

\subsection{Lesson one: light control}

The opening and closure of the lotus: shading louvers that open and close on the southern elevation where the lighting is the most.

Most buildings in the region - the Arabian Gulf - rely on glazing for the building envelope, justifying by abundance in oil and energy. While going back to the simple method of adjustable exterior blinds will raise the U-value of the windows and prevent the sunlight from entering and heating up by glare. This method is close to the strategy that the studied flower, and many others do, which is opening up and closing to allow the desired amount of lighting to enter only. We suggest a simple hung wooden shutter serves best in this building, because it is economic for such a building as the case study, an extra layer of two wooden panels added to the glass windows.

The glass will be treated as well, from being single glazing to a double-glass with a low emissivity coating. This will help to drop the U-value of the windows dramatically.

\subsection{Lesson two: nourishing - mimicking the leaves of the lotus}

We will provide the building with part of its energy through mounted PV cells over the parking lot and the roof, acting like the leaves of the lotus.

\subsubsection{PV calculation}

Through a simple formula, we can roughly estimate how much electricity will be generated from installing these solar panels over the parking area. The formula is: Energy generated $=$ PV area $\mathrm{x}$ invertor efficiency $\mathrm{x}$ battery efficiency $\mathrm{x}$ solar irradiance (we will take the solar irradiance for Dubai).

We currently have $2,360 \mathrm{~m}^{2}$ of parking shade if all were converted into solar panels:

$$
\begin{gathered}
\text { PV area x invertor efficiency x battery efficiency } \times \text { solar irradiance } \\
2360 \times 0.65 \times 0.7 \times 5.5=5905 / \text { day }=177,177 \mathrm{kw} / \text { month }
\end{gathered}
$$

One house consumes approximately $18,000 \mathrm{kw} / \mathrm{month}$ and we have twenty per floor. Total consumption was around 360,000 , meaning that fifty per cent of the needs of this building could be met by solar power.

\subsection{Lesson three: shading}

The shading that the lotus leaves provides keep the fruit in isolation from unwanted exterior lighting and that will be imitated by a double roof created from the building itself to reduce the amount of heat it is exposed to and to provide shade to protect the building. 


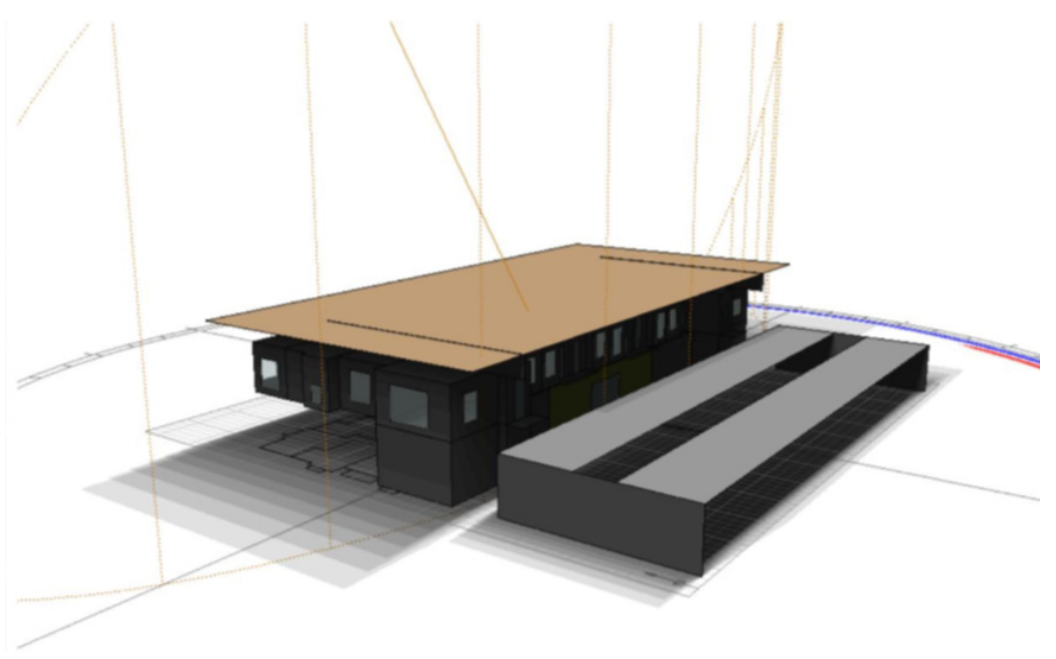

Figure 5: Suggested shading for the building.

\section{Assessing the building after applying the strategies}

With computer modeling, the existing building will be assessed after the modifications - with no major changes applied - as it is a building that has already been constructed. This is to investigate the difference in the behaviour of the building and reaction to the extreme hot summers in Dubai.

Figure 6 shows us the annual sun path after applying the double roof where the building will mostly fall in shade and the sun's output will be well absorbed.

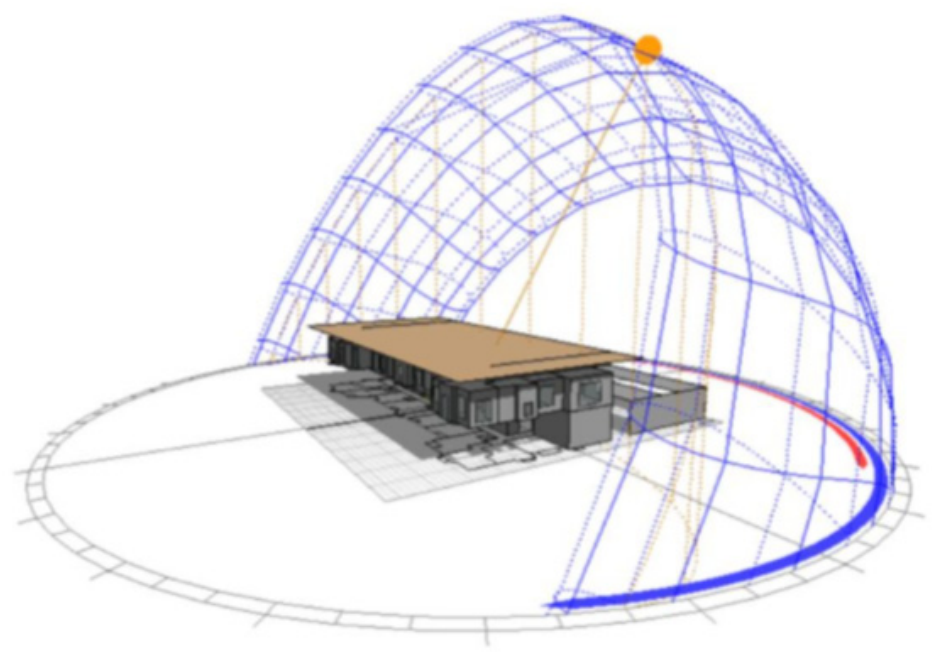

Figure 6: Annual sun path after shading. 
Figure 7 shows the temperature difference outside and inside the zone after several insulation and shading strategies have been applied. The indoor temperature with no artificial cooling is stable in the comfort zone in May and that is a month where we previously needed artificial cooling most of the time.

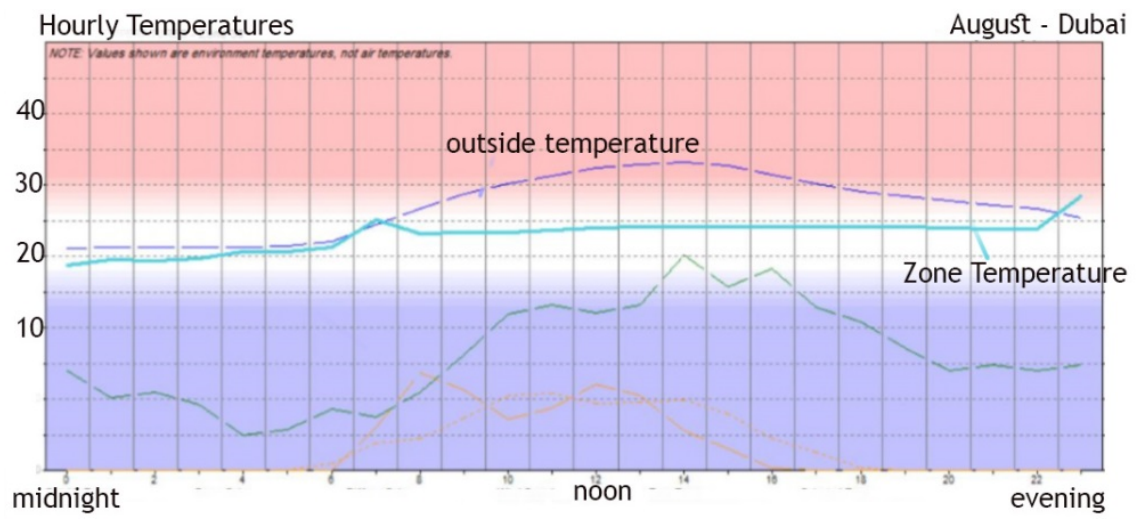

Figure 7: Hourly profile temperature in May, after strategies.

Figure 8 shows a drop from around 49,000 to only $37,066 \mathrm{KW}$ which is a twenty five per cent drop, making the new HVAC load only seventy five per cent of what it was before the modification took place.

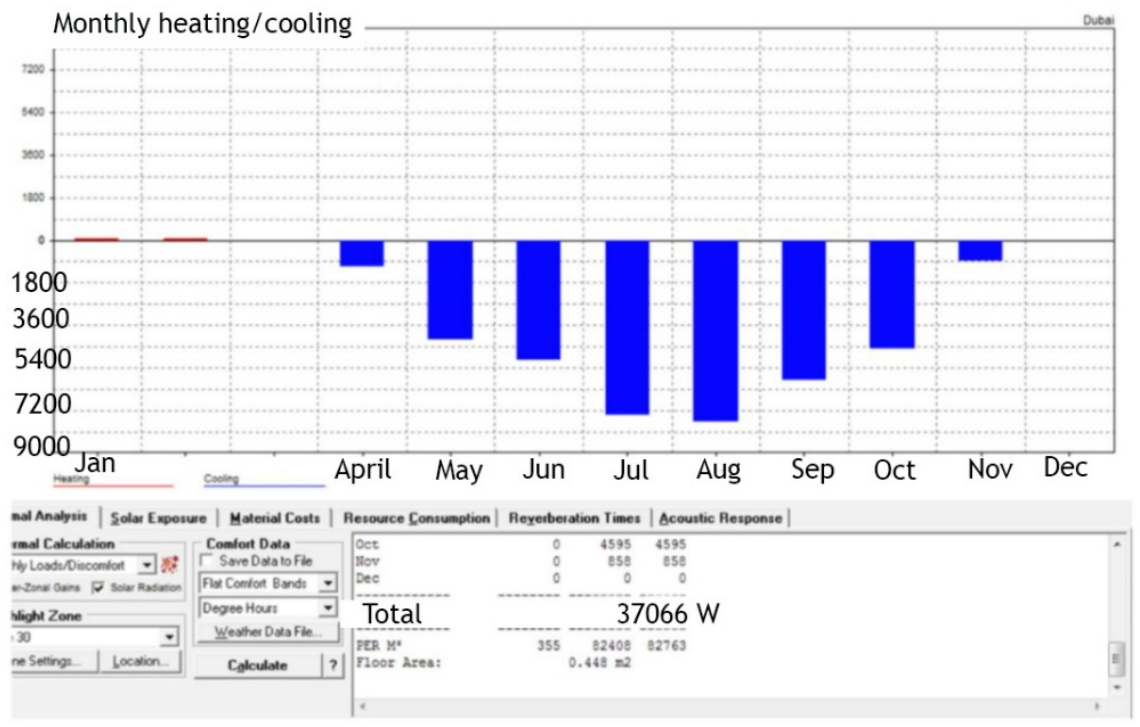

Figure 8: Monthly loads on HVAC system, after strategies. 


\section{Significance of the research}

Biomimicry is trending in architectural research, design, and application. The many lessons inspired by nature are of significance to the architectural development because of the minimalistic yet inspiring approach they take. The minimal changes that were experimented on this building by simulation, showed a significant impact on the building's behaviour and energy consumption. Although the lessons learnt from the lotus flower are not direct, but the imitation of those strategies had a positive ecological effect, and a lot less consumption of energy.

The solar panels have contributed a share of the energy needs of the building and even if they were used for direct water heating and not electricity generation, that will still mean thousands of KWs of clean energy.

The passive design strategies used are of minimal extra cost, yet they provide shade enough to offer the building more protection from the extremely hot and glary sun in this region of the world.

\section{Conclusion}

As architects and urban planners in the world today, our responsibility extends further than engineering and finding conventional solutions for people's problems. It exceeds that, needing innovation which requires our utmost attention and dedication. We need to follow up on the latest trends and discoveries in the field, being aware that thirty eight per cent of greenhouse emissions worldwide are caused by buildings, DOE [3].

Therefore, the study we have begun in this report is more than a mere duty or homework; it is the way all architects and engineers should be operating, making use of technology and human inventions in a positive way, enhance people's lives while saving the planet at the same time.

\section{References}

[1] Penman, V. (2013). Biomimicry. When Nature Inspires Design https://youtube.com.

[2] Pawlyn, M. (2013). Biomimicry in architectural design. http://youtube.com.

[3] US Department of Energy (DOE), 2008 Buildings Energy Data Book, Section 1.1.1, 2008). 